\title{
Structural equivalence in a library and information science journal network in Taiwan
}

\author{
Ya-Ning Chen \\ Department of Information and Library Science, Tamkang University \\ No. 151, Yingzhuan Rd., Tamsui Dist., New Taipei City 25137, TAIWAN \\ e-mail: arthur@tku.edu.tw
}

\begin{abstract}
This study aimed to examine the hidden structures and patterns among Chinese-language library and information science (CLIS) journals in Taiwan according to structural equivalence of social network analysis. Thirteen CLIS journals and 3,150 articles published between 2001 and 2014 were selected as subject and a $13 \times 13$ matrix was aggregated for structural equivalence analysis. The matrix was reduced into $6 \times 6$ blocks, and their block matrices and image diagrams were created based on results of structural equivalence analysis. The six blocks (i.e., general LIS I and II, core LIS I and II, interdisciplinary and residual) were used to examine the journal positions, network images and core-peripheral structure in the network. The block structure of the CLIS journal network shows both stability and change through the two individual periods of seven years (i.e., 2001-2007 and 2008-2014). The structural equivalence based results provide valuable alternative publication outlets for paper re-submission for scholars when a paper has been rejected. Such result is useful for journal editors to gain an image of which journals are competitive rivals in terms of journal-to-journal citation network. The core-periphery structure is roughly supported by this study both for the overall fourteen years and during two individual periods.
\end{abstract}

Keywords: Journal citation network; Structural equivalence; Library and information science (LIS); Social network analysis (SNA); Journal studies.

\section{INTRODUCTION}

Citations are regarded as a social exchange behaviour. Citing and being cited in journal articles acknowledges the knowledge contribution of scholars. Inter-citation among journals has resulted in the seamless buildup of a journal-to-journal (hereafter referred to as J2J) network aggregated by article citations of scholars. Based on a study by Cason and Lubotsky (1936), many studies have been inspired to investigate the structures and 
Chen, Y.N.

patterns hidden in J2J networks, including communication (Reeves and Borgaman 1983; So 1988), consumer behaviour (Zinkhan, Roth and Saxton 1992), demography (Liu and Wang 2005), distance education (Zawacki-Richter and Anderson 2011), economy (Eagly 1975), genetics (McKain 1991), geography (Gartell and Smith 1984), international business (Sullivan, Nerur and Balijepally 2011), LIS (Chen 2018), management (Danell 2000), marketing (Pieters and Baumgartner 2002), psychology (Xhignesse and Osgood 1967) and water pollution and humanization of labor (Leydesdorff 1986).

In addition to bibliometrics, social network analysis (hereafter referred to as SNA) approach has been used to examine the journal's position and role in J2J network. In terms of SNA, journals can be treated as nodes and citations between journals as directional connections to illustrate the social exchange behaviours (i.e., citing and being cited relationships). Since the seminal works published by Doreian (1985) and Doreian and Fararo (1985), the SNA's structural equivalence approach has been employed to investigate whether journals are equivalent to neighbours, that is, they have exactly the same pattern of sending and receiving citations in a J2J network. Furthermore, the blocks and their reduced block matrices and image diagrams offered by structural equivalence analysis can be used to examine the citation relationships between blocks of journals. The results offered by structural equivalence not only provide valuable information for decision-making about highlight alternative publication outlets for scholars when a paper has been rejected (Biehl, Kim and Wade 2006; Polites and Watson 2009), but also serve as a useful reference to help journal editors to discern which journals can be regarded as competitive rivals in sending citations to and receiving citations from similar source journals. However, no study has examined the embedded patterns in a journal citation network both of an overview image and evolutionary change at a field in terms of SNA's structural equivalence.

\section{LITERATURE REVIEW}

The structural equivalence in the social network was defined by Lorrain and White (1971) as "In other words, $a$ is structurally equivalent to $b$ if a relates to every object $x$ of $C$ in exactly the same ways as b does" (p.63). In fact hardly any social actors or nodes are structurally equivalent to others in a social network, exact structural equivalence rarely exists in practice (Breiger, Boorman and Arabie 1975). In empirical applications, Doreian's studies have loosened the original definition of structural equivalence as follows: two nodes can only be regarded as structurally equivalent if they have similar or approximate relationships to all other nodes (Doreian 1985, 1998; Doreian and Fararo 1985). In a J2J citation network, the structural equivalence of SNA is used to investigate whether some 
journals play equivalent roles in terms of social network position by linking to similar citing and cited journals. Some specific journals are nearly interchangeable with similar patterns of citing and cited citations and are almost substitutable to each other in the social network. Although the approach of SNA's structural equivalence can discover the distinctive hidden structures and patterns embedded in J2J networks from bibliometrics, however existing studies adopted structural equivalence as approach to J2J citation network analysis are still rare in recent decades.

Based on eleven sociology journals, Doreian and Fararo (1985) used structural equivalence to analyze various blocks of equivalent journals and their relationships between blocks of three individual periods of two years: 1970-1971, 1975-1976, and 1980-1981. The study tracked the evolution of journals in sociology, and divided journals into five blocks or subgroups. The subgroup of comprehensive sociology journals is the most cited by others across the three periods and a core-periphery hypothesis was highly supported. Doreian (1985) then selected 21 psychology journals as subject to examine the phenomenon of structural equivalence. In this study psychology journals were categorized into two sets of seven subgroups and their citation relationships. A core-periphery structure was also identified in this study. Rice, Borgman and Reeves (1988) used 20 journals in communication between 1977 and 1985 as subject to generalize two structurally equivalent blocks as follows: interpersonal journals and mass media journals. This study also reported that some journals are isolated in terms of structural equivalence. In another study, Doreian (1988) employed structural equivalence to separate 22 geography journals into seven blocks and examined their relationships in 1970-1972 and 1980-1982 respectively, and found that a core-periphery structure existed for journal networks in both periods. Baker (1992) used 20 social work journals between 1985 and 1986 to investigate the characteristics of structural equivalence. In addition six blocks were classified into different categories, this study also found that the core journal block was the most cited block by the other four blocks of journals. Based on 31 journals in academic business disciplines, Biehl, Kim and Wade (2006) identified a set of structural equivalent journals for each journal in 1991 and 2001 respectively, and examined the evolutional change between 1991 and 2001. Polites and Watson (2009) selected the top-125 information system journals from Management and Information Systems' journal rankings webpage of the Association for Information Systems as subject to analyze the structural equivalent blocks in information system discipline. From 2003 to 2005, this study found three core groups (i.e., management, operations research, and pure information system) and six smaller groups. Song and Ye (2009) chose 16 library science and information science journals from the Chinese Social Sciences Citation Index (CSSCl) between 2006 and 2007 as subject to generalize four blocks without assignment of category name. Two are focused on library 
Chen, Y.N.

science (i.e. block 1 and 3 ) and the other two are information science (i.e. block 2 and 4). Block 1 gained more citation from the others and a core-periphery structure was identified in this journal networks.

In Taiwan, Ko, Hsung and Lu (2012) separated 20 Chinese sociology journals into three periods (i.e. 1993-1996, 1997-2000 and 2001-2004) to investigate the hidden citation patterns of structural equivalence in a J2J citation network. This study classified two core subgroups and two isolated subgroups. Furthermore, the social work and social welfare journal subgroup also cited each other within their own subfields. Giannakis (2012) used structural equivalence to categorize ten journals in supply chain management into four blocks in 1991-2000 and 2001-2010 respectively as follows: purchasing and supply management, operations management, logistics and transportation management, and a multi-disciplinary of information systems, logistics and supply chain management. This study also investigated the evolutional change of four blocks and their structurally equivalent members between two periods of ten years. Yue (2012) employed 18 Chinese management science journals in China as subject to examine the characteristics of structural equivalence in 1996-2000 and 2001-2006 respectively. In addition to four blocks (i.e., macroscopic management and policy, technology management, system engineering, and management science) being generalized, this study has also investigated the evolutional change of four blocks and their member journals. Zhao and Wu (2014) employed structural equivalence to classify 16 LIS journals selected from CSSCI into four blocks in 2003-2007 and 2008-2012, respectively, as follows: a core block, a strong edge block, a weak edge block and a periphery block. In addition to examining the evolutional change over two periods, the core-periphery structure was also identified in this study. Chen (2018) used 13 Chinese library and information science journals in Taiwan between 2001 and 2012 as subject for structural equivalence analysis. In addition to an overview image of three blocks between 2001 and 2012, this study has also categorized journals into five blocks and examined the structural equivalent members between three periods of four years (i.e., 2001-2004, 2005-2008 and 2009-2012).

According to the aforementioned review, most studies of structural equivalence are focused on either analyzing the evolutional change between various periods, or identifying the characteristics of structural equivalence in a specified period. Presumably, no study has adopted both several shorter periods to examine the evolutional change, and a longer period to analyze the overview citation patterns embedded in a journal citation network in terms of SNA structural equivalence. In this direction, this paper pursues the following research objectives:

(a) To investigate the structural positions and patterns embedded in the LIS J2J citation 
network in Taiwan in terms of SNA structural equivalence;

(b) To identify the overall citation pattern and the evolutional change hidden in the LIS J2J citation network in Taiwan; and

(c) To examine whether a core-periphery structure has existed in the LIS J2J citation network in Taiwan in terms of structural equivalence analysis.

\section{MATERIALS AND METHOD}

For this study, the Chinese-language Library and Information Science (hereafter referred to as CLIS) journals in Taiwan were selected as subject, as no study has analyzed the journal citation structures and patterns in the context of this setting. According to the registration of the Guide to Periodicals Published in R.O.C. (http://readopac.ncl.edu.tw/nclJournal/), 16 CLIS journals obtained their ISSN under the category of library and information science (LIS) However, two have ceased publication, and five are newsletters with content of reviews, interviews, visiting reports and news of library activities. Several CLIS journals in Taiwan were renamed and continued publishing articles during the period analyzed; this study regarded such journals as one (e.g. JLISR). Thus ten journals were selected for this study. Because LIS is an interdisciplinary field, an additional three LIS related journals (i.e., RECT, AQ and JCEM) were included for this study. In total, thirteen Taiwan LIS journals and 3,150 articles including Chinese and English (Table 1) published from 2001 to 2014 were selected for this study. A 13×13 matrix (Table 2) was aggregated as a basis for J2J citation network analysis and is also more than the minimal limited sets of 10 for local journal map of a specific field (Leydesdorff, de Moya-Anegón and de Nooy 2016).

\section{Time Frame}

The hidden citation patterns of structural equivalence among the Taiwanese CLIS journals was analyzed over fourteen years (2001-2014) with two individual periods of 7 years to conduct the journal citation network analysis. The aforementioned period by aggregated journals is longer than a decade minimally for more reliable J2J network analysis (Leydesdorff, de Moya-Anegón and de Nooy 2016). Then the fourteen year period was divided into two individual periods of seven years each to examine the evolutional change of structural equivalence over two periods. Two individual periods of 7 years are qualified for J2J network analysis, because they have achieved the minimal three years and two time intervals (Leydesdorff 2015), but also can avoid the incidental citation fluctuation and relations (Vugteveen, Lenders and Van den Besselaar 2014). Consequently, using the citation analysis of both the overall and two individual periods, an overview image of a longitudinal period was formed, and the evolutional change between two short individual periods was investigated. 
Table 1: Thirteen Chinese-language LIS Journals in Taiwan and the Articles which were Analyzed

\begin{tabular}{|c|c|c|c|c|c|c|c|c|c|c|c|c|c|c|c|c|c|c|}
\hline \multirow{2}{*}{ Journal Name } & \multirow{2}{*}{ Abbreviation } & \multirow{2}{*}{ Frequency } & \multirow{2}{*}{ Language } & \multicolumn{15}{|c|}{ Publication Year (20-) } \\
\hline & & & & 01 & 02 & 03 & 04 & 05 & 06 & 07 & 08 & 09 & 10 & 11 & 12 & 13 & 14 & Total \\
\hline \multirow{2}{*}{ Journal of Library and Information Science Research } & \multirow{2}{*}{ JLISR } & \multirow{2}{*}{ Semi-annual| } & Chinese & 20 & 24 & 28 & 25 & 41 & 5 & 12 & 10 & 10 & 10 & 9 & 10 & 9 & 10 & 223 \\
\hline & & & English & 0 & 0 & 0 & 0 & 0 & 1 & 0 & 0 & 0 & 0 & 1 & 0 & 1 & 0 & 3 \\
\hline \multirow{2}{*}{ Journal of Library and Information Science } & \multirow{2}{*}{ JLIS } & \multirow{2}{*}{ Semi-annual| } & Chinese & 13 & 10 & 14 & 19 & 15 & 8 & 15 & 9 & 8 & 8 & 9 & 9 & 8 & 12 & 157 \\
\hline & & & English & 6 & 4 & 2 & 5 & 3 & 8 & 5 & 5 & 7 & 5 & 9 & 3 & 4 & 0 & 66 \\
\hline \multirow{2}{*}{ Journal of Educational Media \& Library Sciences } & \multirow{2}{*}{ JOEMLS } & \multirow{2}{*}{ Quarterly } & Chinese & 13 & 17 & 21 & 18 & 24 & 23 & 19 & 16 & 20 & 20 & 17 & 20 & 17 & 13 & 258 \\
\hline & & & English & 16 & 15 & 19 & 21 & 7 & 1 & 4 & 5 & 0 & 0 & 4 & 0 & 1 & 0 & 93 \\
\hline \multirow{2}{*}{ Journal of Library and Information Studies } & \multirow{2}{*}{ JLISS } & \multirow{2}{*}{ Semi-annual } & Chinese & 8 & 7 & 16 & 17 & 12 & 5 & 5 & 5 & 5 & 8 & 7 & 8 & 8 & 8 & 119 \\
\hline & & & English & 1 & 0 & 0 & 1 & 0 & 0 & 0 & 0 & 0 & 4 & 5 & 4 & 4 & 4 & 23 \\
\hline \multirow{2}{*}{ National Central Library Bulletin } & \multirow{2}{*}{ NCLB } & \multirow{2}{*}{ Semi-annual| } & Chinese & 20 & 20 & 21 & 20 & 18 & 12 & 13 & 14 & 11 & 12 & 11 & 13 & 19 & 16 & 220 \\
\hline & & & English & 0 & 0 & 0 & 0 & 0 & 0 & 0 & 0 & 0 & 0 & 1 & 0 & 0 & 0 & 1 \\
\hline \multirow{2}{*}{ University Library Journal } & \multirow{2}{*}{ ULJ } & \multirow{2}{*}{ Semi-annual } & Chinese & 19 & 19 & 18 & 18 & 18 & 16 & 14 & 14 & 14 & 15 & 17 & 16 & 12 & 14 & 224 \\
\hline & & & English & 1 & 0 & 0 & 0 & 0 & 1 & 2 & 2 & 0 & 0 & 0 & 0 & 2 & 0 & 8 \\
\hline \multirow{2}{*}{ Bulletin of Library and Information Science } & \multirow{2}{*}{ BLIS } & \multirow{2}{*}{ Semi-annual| } & Chinese & 31 & 33 & 25 & 28 & 26 & 27 & 26 & 24 & 21 & 20 & 18 & 9 & 8 & 8 & 304 \\
\hline & & & English & 0 & 0 & 0 & 0 & 0 & 0 & 0 & 3 & 2 & 0 & 1 & 2 & 1 & 0 & 9 \\
\hline \multirow[t]{2}{*}{ Research of Educational Communications and } & \multirow{2}{*}{ RECT } & \multirow{2}{*}{ Quarterly } & Chinese & 33 & 29 & 26 & 24 & 26 & 24 & 27 & 28 & 23 & 24 & 16 & 17 & 16 & 13 & 326 \\
\hline & & & English & 0 & 0 & 0 & 0 & 0 & 0 & 0 & 0 & 1 & 0 & 1 & 1 & 0 & 0 & 3 \\
\hline
\end{tabular}




\begin{tabular}{|c|c|c|c|c|c|c|c|c|c|c|c|c|c|c|c|c|c|c|}
\hline \multirow{2}{*}{ Archives Quarterly } & \multirow{2}{*}{$\mathrm{AQ}$} & \multirow{2}{*}{ Quarterly } & Chinese & 11 & 55 & 74 & 50 & 51 & 42 & 35 & 37 & 44 & 43 & 30 & 33 & 31 & 33 & 569 \\
\hline & & & English & 0 & 0 & 0 & 0 & 0 & 1 & 0 & 0 & 0 & 0 & 1 & 1 & 0 & 0 & 3 \\
\hline \multirow{2}{*}{ Journal of Cultural Enterprise and Management } & \multirow{2}{*}{ JCEM } & \multirow{2}{*}{ Semi-annual } & Chinese & 0 & 0 & 0 & 4 & 0 & 7 & 5 & 5 & 11 & 8 & 13 & 12 & 7 & 6 & 78 \\
\hline & & & English & 0 & 0 & 0 & 0 & 0 & 0 & 0 & 0 & 0 & 1 & 1 & 0 & 0 & 0 & 2 \\
\hline \multirow{2}{*}{ Information Management for Buddhist Libraries } & \multirow{2}{*}{ IMBL } & \multirow{2}{*}{ Semi-annual } & Chinese & 23 & 24 & 21 & 23 & 21 & 20 & 18 & 27 & 20 & 8 & 16 & 17 & 14 & 12 & 264 \\
\hline & & & English & 0 & 0 & 0 & 0 & 0 & 0 & 0 & 0 & 0 & 0 & 0 & 0 & 0 & 0 & 0 \\
\hline \multirow[t]{2}{*}{ Journal of Information, Communication, and Library } & \multirow{2}{*}{ JICLS } & \multirow{2}{*}{ Monthly } & Chinese & 34 & 30 & 10 & 6 & 6 & 11 & 0 & 0 & 0 & 0 & 0 & 0 & 0 & 0 & 97 \\
\hline & & & English & 6 & 3 & 0 & 0 & 1 & 0 & 0 & 0 & 0 & 0 & 0 & 0 & 0 & 0 & 10 \\
\hline \multirow{2}{*}{ National Cheng Kung University Library Journal } & \multirow{2}{*}{ NCKULJ } & \multirow{2}{*}{ Annual } & Chinese & 6 & 11 & 12 & 5 & 9 & 8 & 7 & 6 & 4 & 4 & 2 & 5 & 4 & 7 & 90 \\
\hline & & & English & 0 & 0 & 0 & 0 & 0 & 0 & 0 & 0 & 0 & 0 & 0 & 0 & 0 & 0 & 0 \\
\hline
\end{tabular}


Table 2: Relationship Between Citing Journal (Vertical Axis) and Cited Journal (Horizontal Axis)

\begin{tabular}{|c|c|c|c|c|c|c|c|c|c|c|c|c|c|c|c|c|c|c|c|c|c|}
\hline & \multicolumn{3}{|c|}{ JLISR } & \multicolumn{3}{|c|}{ JLIS } & \multicolumn{3}{|c|}{ JOEMLS } & \multicolumn{3}{|c|}{ JLISS } & \multicolumn{3}{|c|}{ NCLB } & \multicolumn{3}{|c|}{ ULJ } & \multicolumn{3}{|c|}{ BLIS } \\
\hline & 01 & 08 & 01 & 0 & 08 & 01 & 01 & 08 & 01 & 01 & 08 & 01 & 01 & 08 & 01 & 01 & 08 & 01 & 01 & 08 & 01 \\
\hline & - & - & - & - & - & - & - & - & - & - & - & - & - & - & - & - & - & - & - & - & - \\
\hline & 07 & 14 & 14 & 07 & 14 & 14 & 07 & 14 & 14 & 07 & 14 & 14 & 07 & 14 & 14 & 07 & 14 & 14 & 07 & 14 & 14 \\
\hline ISR & 4 & 3 & 74 & 11 & 6 & 17 & 13 & 17 & 30 & 11 & 1 & 22 & 20 & 8 & 28 & 23 & 11 & 34 & 28 & 15 & 43 \\
\hline & & 15 & 2 & 6 & 0 & 26 & 15 & 15 & 30 & 5 & 5 & 20 & 9 & 6 & 15 & 11 & 18 & 29 & 7 & 11 & 18 \\
\hline 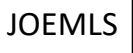 & 34 & 22 & 56 & 17 & 2. & 41 & 39 & 52 & 91 & 13 & 13 & 26 & 13 & 9 & 22 & 19 & 20 & 39 & 17 & 18 & 35 \\
\hline SS & 12 & 19 & 31 & 7 & 6 & 13 & 12 & 17 & 29 & 8 & 17 & 25 & 3 & 3 & $\epsilon$ & 11 & 14 & 25 & 5 & 11 & 16 \\
\hline CLB & 4 & 18 & 65 & 11 & 16 & 27 & 14 & 11 & 25 & 2 & - & 7 & 24 & 30 & 54 & 13 & 12 & 25 & 19 & 13 & 32 \\
\hline 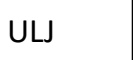 & 49 & 14 & 63 & 16 & 12 & 28 & 25 & 29 & $\mid 54$ & 11 & 6 & 17 & 10 & 18 & 28 & 35 & 24 & 59 & 36 & 26 & 62 \\
\hline IS & 7 & 23 & 95 & 15 & 12 & 27 & 29 & 22 & 51 & 8 & 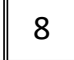 & 18 & 23 & 13 & 36 & 45 & 24 & 69 & 74 & 29 & 103 \\
\hline NEC, & 8 & 1 & 9 & 6 & 9 & 15 & 9 & 22 & 3 & 1 & 4 & 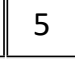 & 0 & 1 & + & 5 & 4 & 9 & 8 & 2 & 10 \\
\hline$A Q$ & e & 6 & 5 & 3 & 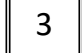 & . & 0 & 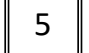 & 5 & 0 & 3 & 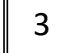 & 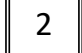 & 5 & r & 11 & 13 & 24 & 12 & 11 & 23 \\
\hline EM & 0 & 2 & 2 & 0 & 0 & 0 & 0 & 2 & 2 & 0 & 1 & 1 & 0 & 0 & 0 & 1 & 0 & 1 & 0 & 1 & 1 \\
\hline IMBL & 10 & 0 & 10 & 5 & 0 & 5 & 2 & 0 & 2 & 1 & 0 & 1 & 1 & 1 & 2 & 6 & 0 & 6 & 4 & 0 & 4 \\
\hline LS & 7 & 0 & 1 & 2 & 0 & 2 & 4 & 0 & 4 & 2 & 0 & 2 & 0 & 0 & 0 & 7 & 0 & 1 & 3 & 0 & 3 \\
\hline$K U$ & 8 & 0 & ${ }^{\circ}$ & 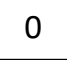 & 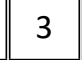 & 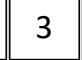 & 3 & 2 & 5 & 0 & 2 & 2 & 1 & 3 & 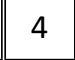 & $\mid 11$ & 3 & 13 & $\gamma$ & 9 & 17 \\
\hline Total $^{\mathrm{a}}$ & 08 & $\mid 144$ & 452 & 99 & 111 & 210 & $\mid 165$ & $\mid 194$ & | 359 & 62 & 85 & 149 & 106 & $\mid 97$ & 203 & 198 & 143 & 340 & 221 & 146 & 367 \\
\hline
\end{tabular}

Table 2 (continued)

\begin{tabular}{|c|c|c|c|c|c|c|c|c|c|c|c|c|c|c|c|c|c|c|c|c|c|}
\hline & \multicolumn{3}{|c|}{ RECT } & \multicolumn{3}{|c|}{$A Q$} & \multicolumn{3}{|c|}{ JCEM } & \multicolumn{3}{|c|}{ IMBL } & \multicolumn{3}{|c|}{ JICLS } & \multicolumn{3}{|c|}{ NCKULJ } & \multicolumn{3}{|c|}{ Total ${ }^{b}$} \\
\hline & 01 & 08 & 01 & 01 & 08 & 01 & 01 & 08 & 01 & 01 & 08 & 01 & 01 & 08 & 01 & 01 & 08 & 01 & 01 & 08 & 01 \\
\hline & - & - & - & - & - & - & - & - & - & - & - & - & - & - & - & - & - & - & - & - & - \\
\hline & 07 & 14 & 14 & 07 & 14 & 14 & 07 & 14 & 14 & 07 & 14 & 14 & 07 & 14 & 14 & 07 & 14 & 14 & 07 & 14 & 14 \\
\hline JLISR & 3 & 0 & 3 & 2 & 2 & 4 & 0 & 0 & 0 & 2 & 3 & 5 & 30 & 2 & 32 & 10 & 1 & 11 & 197 & 106 & 303 \\
\hline JLIS & 10 & 4 & 14 & 0 & 3 & 3 & 0 & 0 & 0 & 4 & 2 & 6 & 13 & 3 & 16 & 1 & 2 & 3 & 93 & 114 & 207 \\
\hline JOEMLS & 33 & 15 & 48 & 4 & 9 & 13 & 0 & 0 & 0 & 3 & 2 & 5 & 28 & 10 & 38 & 10 & 11 & 21 & 230 & 205 & 435 \\
\hline JLISS & 2 & 2 & 4 & 0 & 0 & 0 & 0 & 0 & 0 & 0 & 0 & 0 & 7 & 4 & 11 & 2 & 1 & 3 & 69 & 94 & 163 \\
\hline NCLB & 0 & 0 & 0 & 9 & 4 & 13 & 0 & 0 & 0 & 13 & 4 & 17 & 12 & 4 & 16 & 2 & 2 & 4 & 166 & 119 & 285 \\
\hline ULJ & 6 & 3 & 9 & 14 & 10 & 24 & 0 & 0 & 0 & 3 & 3 & 6 & 30 & 1 & 31 & 4 & 6 & 10 & 239 & 152 & 391 \\
\hline BLIS & 2 & 1 & 3 & 4 & 10 & 14 & 0 & 0 & 0 & 8 & 2 & 10 & 27 & 9 & 36 & 8 & 8 & 16 & 315 & 161 & 478 \\
\hline RECT & 120 & 82 & 202 & 0 & 0 & 0 & 0 & 0 & 0 & 0 & 0 & 0 & 6 & 2 & 8 & 1 & 0 & 1 & 164 & 127 & 291 \\
\hline
\end{tabular}




\begin{tabular}{l|c|c||c|c|c|c|c|c|c|c||c|c||c||c||c||c||c||c||c||c||c}
\hline \hline $\mathrm{AQ}$ & $\mathbf{0}$ & 0 & 0 & 140 & 92 & 232 & 0 & 0 & 0 & 3 & 1 & 4 & 6 & 0 & 6 & 1 & 4 & 5 & 183 & 137 & 320 \\
\hline \hline $\mathrm{JCEM}$ & $\mathbf{0}$ & 1 & 1 & 0 & 0 & 0 & 0 & 3 & 3 & 1 & 0 & 1 & 0 & 1 & 1 & 0 & 0 & 0 & 2 & 11 & 13 \\
\hline \hline $\mathrm{IMBL}$ & $\mathbf{0}$ & 0 & 0 & 1 & 0 & 1 & 0 & 0 & 0 & 36 & 38 & 74 & 10 & 0 & 10 & 0 & 0 & 0 & 76 & 39 & 115 \\
\hline \hline $\mathrm{JICLS}$ & $\mathbf{3}$ & 0 & 3 & 0 & 0 & 0 & 0 & 0 & 0 & 0 & 0 & 0 & 12 & 0 & 12 & 0 & 0 & 0 & 40 & 0 & 40 \\
\hline \hline NCKULJ & $\mathbf{0}$ & 0 & 0 & 0 & 0 & 0 & 0 & 0 & 0 & 3 & 0 & 3 & 2 & 0 & 2 & 3 & 0 & 3 & 39 & 22 & 60 \\
\hline \hline Total $^{\text {a }}$ & $\mathbf{1 7 9}$ & 108 & 287 & 174 & 130 & 304 & 0 & 3 & 3 & 76 & 55 & 131 & 183 & 36 & 219 & 42 & 35 & 77 & 1813 & 1287 & 3101 \\
\hline \hline
\end{tabular}

$a=$ receiving citations, $b=$ sending citations

\section{Processing}

First, the journals were treated as nodes and citations between journals as directional connections to illustrate the citing and cited relationships between journals as social exchange behaviours in terms of SNA. Next, the original definition of exact structural equivalence proposed by Lorrain and White (1971) was applied for studies of empirical applications. The structural equivalence can be defined as follows: "letting $x_{i j r}$ indicate the presence or absence of a tie from actor $i$ to actor $j$ on relation $x_{r}$, then actors $i$ and $j$ are structurally equivalent if $x_{i k r}=x_{j k r}$ and $x_{k i r}=x_{k j r}$ for $k=1,2, \cdots, g$, and $r=1,2, \cdots, R$. " (Wasserman and Faust 1994, p.357). The definition has been loosened to fit empirical studies based on the premise that only if two nodes share the similar or approximate relationships to all other nodes, can they be regarded as structurally equivalent. This study followed the loose definition of SNA structural equivalence adopted by previous studies discussed in the literature review section. Accordingly, using the concept of structural equivalence, journals can be grouped into different specialities or subfields within a discipline and detect the interaction among subfields (Biehl, Kim and Wade 2006). In terms of SNA, the aforementioned subfield based journal groups (i.e., blocks) are structurally nonequivalent positions and each is composed of structurally equivalent journals (Doreian 1985). This study employed the SNA structural equivalence to analyze the structure of the Taiwan CLIS journal citation network when nodes were the blocks (i.e., subfield based journal groups). Furthermore, Euclidean distance was used to measure the degree of structural equivalent pattern embedded in the Taiwan CLIS journal citation network. If the degree is equal to zero, it reveals that two network actors are perfectly equivalent. On the other hand, if the degree increases with the extent to one, then two network actors are involved in the distinctive patterns of relationships (Burt, 1987). Journal $i$ and $j$ are structurally equivalent in a J2J network if the Euclidean distance $d_{i j}$ between their respective J2J network position is zero (Burt 1987; Wasserman and Faust 1994). The Euclidean distance between journal $i$ and $j$ is formally defined as follows (Burt 1987): 
Chen, Y.N.

$$
d_{i j}=\sqrt{\sum_{k}\left(\frac{Z_{i k}}{R_{i}}-\frac{Z_{j k}}{R_{j}}\right)^{2}+\sum_{k}\left(\frac{Z_{k i}}{C_{i}}-\frac{Z_{k j}}{C_{j}}\right)^{2}}, i \neq j \neq k
$$

Fourth, following Doreian and Fararo (1985) and Doreian (1985), the citing and cited relationships (i.e., correlation) between blocks of structurally equivalent journals were converted into image matrices by adoption of the mean overall density of Taiwan CLIS journal citation network as cutoff value. Fifth, journal self-citations were also included in this study to examine whether Taiwan CLIS journals cite each other within their own subfields. UciNet 6 software was used to examine the hidden structures and patterns embedded among the CLIS journals in Taiwan in terms of SNA's structural equivalence.

\section{RESULTS AND DISCUSSION}

\section{Journal Positions}

From 2001 to 2014, five blocks of structural equivalence were clustered as follows: interdisciplinary LIS, general LIS, core LIS I, core LIS II and residual LIS (Figure 1 and Table 3) in terms of journal's objectives and their topics of published articles. There was one very clear interdisciplinary cluster comprising JLIS, RECT, JICLS and NCKULJ. This is an interdisciplinary subgroup related to educational technology, publishing and the book, and communication within the network. The second cluster to emerge comprised AQ and IMBL. This grouping cluster is viewed as having a general LIS position within the network, and is a mixed group concerned with the coverage of various topics related to archival and Buddhism studies in Taiwan LIS field. The third cluster is a core LIS I composed of JOEMLS and ULJ. This cluster is viewed as a core LIS subgroup, and the coverage of these two journals is focused on research-based or evidence-based LIS. The fourth cluster is composed of JLISR, JLISS, NCLB and BLIS. This is another core LIS group in titles reflecting the areas of research-based LIS, Chinese study, and interdisciplinary study including digital libraries, elearning, and digital humanities. The fifth cluster that emerged comprised JCEM. This journal is not cited by other LIS journals in Taiwan, and is a residual group in title reflecting cultural industry and management. In terms of SNA, this journal is almost isolated from other Taiwan LIS journals within the network.

In terms of evolutional change (Figure 1 and Table 3), the first cluster represents the interdisciplinary category. The number of members of this cluster has remained as two both over the first period and over the second period of seven years, and then aggregated into four members over overall of fourteen years. It reveals that the area of 
interdisciplinary has not only gained attention in Taiwan LIS field in recent years, but has also extended coverage into various topics, including educational technology, and communication, according to the coverage of JLIS, RECT, JICLS and NCKUL. Furthermore, JLIS has gradually become the key member of this cluster between the second period and overall of fourteen years.
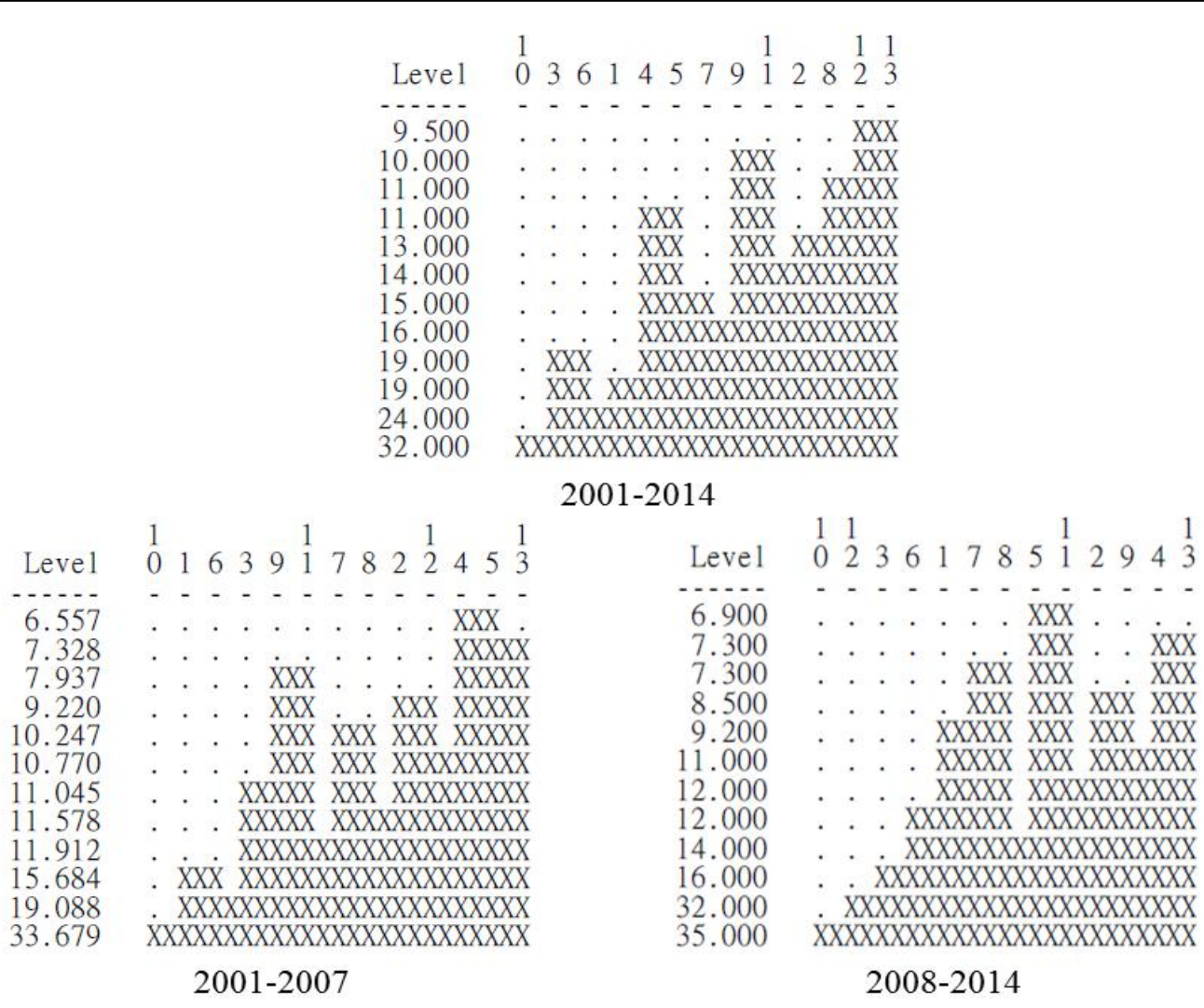

Figure 1: Cluster Diagram for Chinese-language LIS Journals in Taiwan (2001-2014) under Conditions of Structural Equivalence

Next, the second and the third cluster reflected the general LIS journals. The number of members changed from six to four from the first to the second period. JJLISS, NCLB, IMBL and NCKUL were key members of general LIS category over the two individual periods. JOEMLS and AQ joined during the first period, and left during the second period. This shows that the general LIS II category is inclined towards general LIS with less focus on archives and publishing and the book, when JOEMLS and AQ are excluded from this cluster. When moved from the first to the second period, the second cluster (i.e., general LIS I) is inclined towards general LIS by exclusion of NCLB with less focus on Chinese studies. On the other hand, in addition to general LIS and Buddhism study, the focus of the third cluster (i.e., general LIS II) has changed from archives to Chinese studies with a member switch between JOEMLS and AQ, and NCLB. When extending the longitudinal period from two 
Chen, Y.N.

individual seven years into overall of fourteen years, number of general LIS clusters in Taiwan CLIS journals has diminished from six to two. This implies that the number of member of general LIS category in Taiwan LIS journals has decreased gradually in recent years.

Table 3: Categorization According to Structural Equivalence Analysis

\begin{tabular}{|c|c|c|c|c|}
\hline \multirow[t]{2}{*}{ Category Name (No.) } & \multirow[t]{2}{*}{ Definition of Category } & \multicolumn{3}{|c|}{ Journals } \\
\hline & & $2001-2007$ & 2008-2014 & 2001-2014 \\
\hline Interdisciplinary LIS (1) & $\begin{array}{l}\text { The focus of this category is not only LIS, } \\
\text { but also a interdisciplinary topics, such as } \\
\text { archival study, and educational technology } \\
\text { and communication. }\end{array}$ & $\begin{array}{l}\text { BLIS \& } \\
\text { RECT }\end{array}$ & JLIS \& AQ & $\begin{array}{l}\text { JLIS, RECT, } \\
\text { JICLS \& } \\
\text { NCKULJ }\end{array}$ \\
\hline General LIS I (2) & $\begin{array}{l}\text { This category is focused on a broad } \\
\text { spectrum of LIS study and is inclined } \\
\text { towards Chinese study. }\end{array}$ & $\begin{array}{l}\text { JLISS, NCLB } \\
\& \text { NCKULJ }\end{array}$ & $\begin{array}{l}\text { JLISS \& } \\
\text { NCKULJ }\end{array}$ & \\
\hline General LIS II (3) & $\begin{array}{l}\text { This is another category focused on a broad } \\
\text { spectrum of LIS study, and it tends towards } \\
\text { topics related to archival study and } \\
\text { Buddhism study. }\end{array}$ & $\begin{array}{l}\text { JOEMLS, } \\
\text { AQ \& IMBL }\end{array}$ & $\begin{array}{l}\text { NCLB \& } \\
\text { IMBL }\end{array}$ & $A Q \& I M B L$ \\
\hline Core LIS I (4) & $\begin{array}{l}\text { This category is a key publication outlet of } \\
\text { LIS paper submission in Taiwan which is } \\
\text { focused on either research or evidence } \\
\text { orientation. The coverage of this category is } \\
\text { inclined towards topics of educational } \\
\text { technology and communication. }\end{array}$ & JLIS \& JICLS & $\begin{array}{l}\text { JOEMLS \& } \\
\text { ULJ }\end{array}$ & $\begin{array}{l}\text { JOEMLS \& } \\
\text { ULJ }\end{array}$ \\
\hline Core LIS II (5) & $\begin{array}{l}\text { This category is another key publication } \\
\text { outlet of LIS paper submission in Taiwan } \\
\text { which is focused on either research or } \\
\text { evidence orientation. The coverage of this } \\
\text { category is more inclined towards issues } \\
\text { related to educational technology and } \\
\text { communication, and Chinese study. }\end{array}$ & JLISR \& ULJ & $\begin{array}{l}\text { JLISR, BLIS } \\
\& \text { RECT }\end{array}$ & $\begin{array}{l}\text { JLISR, JLISS, } \\
\text { NCLB \& } \\
\text { BLIS }\end{array}$ \\
\hline Residual (6) & $\begin{array}{l}\text { This category is a residual group which is } \\
\text { little related to LIS issues. }\end{array}$ & JCEM & $\begin{array}{l}\text { JCEM \& } \\
\text { JICLS }\end{array}$ & JCEM \\
\hline
\end{tabular}

Third, the fourth and fifth cluster represents the position of core LIS category in Taiwan LIS field. JLISR and ULJ were key members of the core LIS cluster both over overall of fourteen 
years and two individual periods of seven years, and have split into distinctive individual core LIS cluster accompanying with different members during the second and overall period. JLIS and JICLS joined the first core LIS cluster during the first period, JOEMLS joined the first core LIS cluster with ULI during the second and overall period, and BLIS and RECT joined the second core LIS cluster with JLISR during the second period. In addition to research-based LIS, the focus of the first core LIS cluster has changed from communication (i.e., JICLS) to evidence-based LIS (i.e. ULI), owing to change of joined members. On the other hand, the focus of the second core LIS cluster has changed from evidence-based LIS into more interdisciplinary topics, such as educational technology and communication, digital libraries, e-learning and digital humanities with inclusion of BLIS and RECT.

Fourth, the sixth cluster represents the residual position in the Taiwan LIS field. The number of members changed from one to two during from the first to the second period. Owing to the coverage of cultural industry and management, JCEM is naturally isolated from and not cited by other Taiwan CLIS journals. The reason of the isolation of JICLS from other Taiwan LIS journals during the second period is distinctive from JCEM in that JICLS ceased publication after 2007. Thus JICLS citations, both received and sent from other Taiwan LIS journals, have gradually decreased.

In terms of networking position, JLISS and NCKUL occupied the same position (i.e., general LIS I) in both of the individual periods. IMBL, JCEM and JLISR and UL occupied the same position both overall over fourteen years and over the two individual periods of seven years, but they have played a different role in the Taiwan LIS network, including the general LIS, residual LIS and core LIS categories. Furthermore, BLIS and JOEMLS were categorized as a member of the core LIS category both in the second individual period and over overall of fourteen years. This implies that BLIS and JOEMLS have gradually as members of the core LIS category in Taiwan. The most interesting point that deserves note is that JLISS and NCLB have gradually become members of core LIS category through a synergistic effect by aggregative J2J citations in terms of the overall period of fourteen years. On the other hand, JLIS joined the core LIS I and interdisciplinary LIS, JOEMLS joined general LIS II and core LIS I category, BLIS and RECT joined interdisciplinary LIS and core LIS II, AQ joined the general LIS II and interdisciplinary LIS, and JICLS joined the core LIS I and residual LIS category respectively in the evolution over the two individual periods. This implies that JLIS, JOEMLS, BLIS, RECT, AQ and JICLS have not stayed in the same cluster to compete in sending and receiving citations from other CLIS journals in Taiwan. 
Chen, Y.N.

\section{Network Images}

For the longitudinal period 2001-2014, the mean density was 18.349 . Mean density was used as a cutoff value, above which densities are coded as 1 and below which they are coded as 0 . According to the five blocks identified from Figure 1 and Table 3 , the $13 \times 13$ matrix was reduced to a $6 \times 6$ block matrix with densities of ties between blocks (Figure 2 and Table 4). There are three positions receiving ties from elsewhere in the structure and they are interdisciplinary (position 1), core LIS I (position 4) and core LIS II (position 5). The remaining one position (i.e., position 6-residual LIS) is completely isolated in the image structure and the other one (i.e., general LIS I) is disappeared. This also indicates that interdisciplinary, general LIS II, core LIS I and core LIS II journals also cited each other within their own subgroup; the exception was residual LIS. Roughly, three core position (i.e., interdisciplinary LIS, core LIS I and core LIS II) and two peripheral position exist, and this structure is too diverse in the structure. However, this structure reveals that interdisciplinary LIS, core LIS I and core LIS II has gained more prominence than general LIS II and residual LIS.

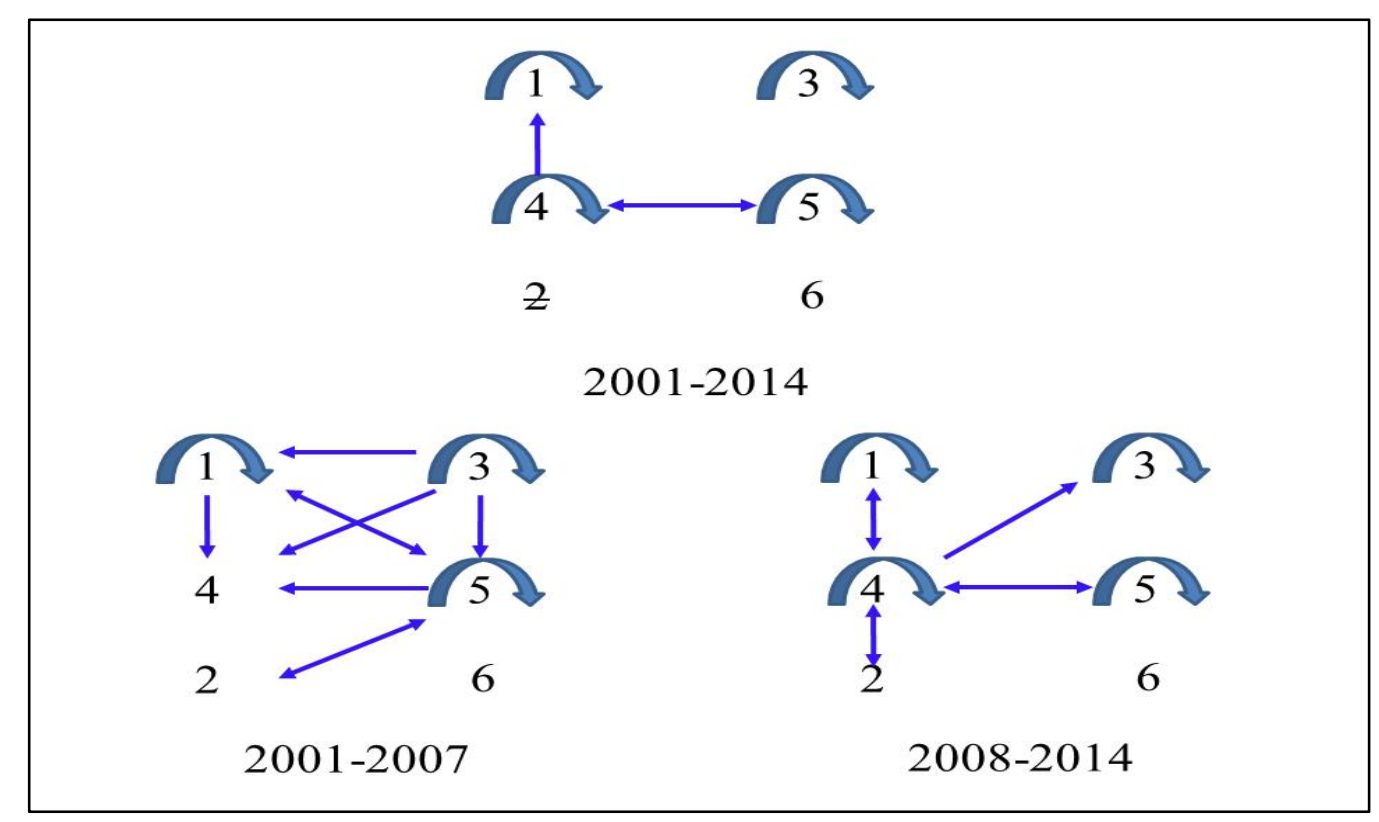

Figure 2: Image Graphs of Blocked Positions. (1) Interdisciplinary LIS (2) General LIS I (3) General LIS II (4) Core LIS I (5) Core LIS II (6) Residual/ancillary.

Notes: The arrow is used to indicate which one block has sent citation to the other one, i.e., starting point of arrow is a citing block and end point of arrow direction is a cited block. If the arrow direction is bi-directional, it means that two blocks cite each other. If a block number is enclosed by a semi-circle, it means that the enclosed block is self-cited. If a block number is indicated with a single deleted line, it means that the block has not formulated as a cluster existing in journal network. 
Table 4: Tie Density Matrix and Image Matrics Between Blocks 2001-2014

\begin{tabular}{|c|c|c|c|c|c|c|}
\hline \multicolumn{7}{|c|}{ Tie density matrix (mean density $=18.349$ ) } \\
\hline & 1 & 2 & 3 & 4 & 5 & 6 \\
\hline 1 & 19.375 & - & 1.500 & 16.000 & 9.250 & 0.000 \\
\hline 2 & - & - & - & - & - & - \\
\hline 3 & 4.000 & - & 77.750 & 9.250 & 6.875 & 0.000 \\
\hline 4 & 28.250 & - & 12.000 & 60.750 & 38.625 & 0.000 \\
\hline 5 & 13.938 & - & 7.875 & 36.000 & 40.938 & 0.000 \\
\hline 6 & 0.500 & - & 0.500 & 1.500 & 1.000 & 3.000 \\
\hline \multicolumn{7}{|c|}{ Image matrics } \\
\hline & 1 & 2 & 3 & 4 & 5 & 6 \\
\hline 1 & 1 & - & 0 & 0 & 0 & 0 \\
\hline 2 & - & - & - & - & - & - \\
\hline 3 & 0 & - & 1 & 0 & 0 & 0 \\
\hline 4 & 1 & - & 0 & 1 & 1 & 0 \\
\hline 5 & 0 & - & 0 & 1 & 1 & 0 \\
\hline 6 & 0 & - & 0 & 0 & 0 & 0 \\
\hline \multicolumn{7}{|l|}{ Legend } \\
\hline 1: & \multicolumn{6}{|c|}{ JLIS, RECT, JICLS \& NCKULJ (Interdisciplinary LIS category) } \\
\hline 2: & \multicolumn{6}{|c|}{ - $\quad$ (General LIS I category) } \\
\hline 3: & \multicolumn{6}{|c|}{ AQ \& IMBL (General LIS II category) } \\
\hline 4: & \multicolumn{6}{|c|}{ JOEMLS \& ULJ (Core LIS I category) } \\
\hline 5: & \multicolumn{6}{|c|}{ JLISR, JLISS, NCLB \& BLIS (Core LIS II category) } \\
\hline 6: & \multicolumn{6}{|c|}{ JCEM (Residual category) } \\
\hline
\end{tabular}

In terms of the first period from 2001 to 2007 , the mean density is 10.728 . Following the aforementioned coding task, a $6 \times 6$ block matrix with densities of ties between blocks (Figure 2 and Table 5) was generated. Interdisciplinary LIS, general LIS I, core LIS I and core LIS II had ties to elsewhere in the structure. Only one position (i.e., residual LIS) is completely isolated in the image structure. This also indicates that interdisciplinary, general LIS II and core LIS II also cited each other within their own subgroup. Roughly, two core position (i.e., core LIS I and core LIS II) and three peripheral position (i.e., interdisciplinary LIS, general LIS I and general LIS II) exist in this structure. This implies that core LIS I and II have tighter interactive information flow and has also gained the most prominence than other LIS categories. 
Table 5: Tie Density Matrix and Image Matrics Between Blocks 2001-2007

\begin{tabular}{|c|c|c|c|c|c|c|}
\hline \multicolumn{7}{|c|}{ Tie density matrix (mean density $=10.728)$} \\
\hline & 1 & 2 & 3 & 4 & 5 & 6 \\
\hline 1 & 51.000 & 6.833 & 8.333 & 13.500 & 32.500 & 0.000 \\
\hline 2 & 5.667 & 5.000 & 6.000 & 6.500 & 17.000 & 0.000 \\
\hline 3 & 11.000 & 4.556 & 25.333 & 11.500 & 14.167 & 0.000 \\
\hline 4 & 5.750 & 2.833 & 3.833 & 8.250 & 9.250 & 0.000 \\
\hline 5 & 18.250 & 11.000 & 9.833 & 21.750 & 37.750 & 0.000 \\
\hline 6 & 0.000 & 0.000 & 0.333 & 0.000 & 0.500 & 0.000 \\
\hline \multicolumn{7}{|c|}{ Image matrics } \\
\hline & 1 & 2 & 3 & 4 & 5 & 6 \\
\hline 1 & 1 & 0 & 0 & 1 & 1 & 0 \\
\hline 2 & 0 & 0 & 0 & 0 & 1 & 0 \\
\hline 3 & 1 & 0 & 1 & 1 & 1 & 0 \\
\hline 4 & 0 & 0 & 0 & 0 & 0 & 0 \\
\hline 5 & 1 & 1 & 0 & 1 & 1 & 0 \\
\hline 6 & 0 & 0 & 0 & 0 & 0 & 0 \\
\hline \multicolumn{7}{|l|}{ Legend } \\
\hline 1: & \multicolumn{6}{|c|}{ BLIS \& RECT (Interdisciplinary LIS category) } \\
\hline 2: & \multicolumn{6}{|c|}{ JLISS, NCLB \& NCKULJ (General LIS I category) } \\
\hline 3: & \multicolumn{6}{|c|}{ JOEMLS, AQ \& IMBL (General LIS II category) } \\
\hline 4: & \multicolumn{6}{|c|}{ JLIS \& JICLS (Core LIS I category) } \\
\hline 5: & \multicolumn{6}{|c|}{ JLISR \& ULJ (Core LIS II category) } \\
\hline 6: & \multicolumn{6}{|c|}{ JCEM (Residual category) } \\
\hline
\end{tabular}

In the second period between 2008 and 2014, the mean density declined to 7.615. A 6x6 block matrix with densities of ties between blocks (Figure 2 and Table 6) was also generated. Five positions (i.e., interdisciplinary LIS, general LIS I, general LIS II, core LIS I and core LIS II) have gained ties from elsewhere in the structure and one positions (i.e., residual LIS) is completely isolated. This also echoes a similar result to 2001-2014 in that interdisciplinary LIS, general LIS II, core LIS I and core LIS II cited each other within their own subgroup. Roughly, this structure has one position in the core and four in the peripheral. This means that core LIS I category has gained the most prominence during this period. Lastly, one point from the aforementioned analysis deserves note. The result of this study is different from other studies (Baker 1992; Doreian 1985, 1998; Doreian and Fararo 1985 ) in that only three subgroups did not cite each other within their own subgroup: 
general LIS I and residual LIS (i.e., overall and two individual periods) and core LIS I (i.e., the first period). The reason for this may be that many CLIS journal articles in Taiwan cite English LIS literature and other non-LIS fields (Huang 2008).

Table 6: Tie Density Matrix and Image Matrics Between Blocks 2008-2014

\begin{tabular}{|c|c|c|c|c|c|c|}
\hline \multicolumn{7}{|c|}{ Tie density matrix (mean density $=7.165$ ) } \\
\hline & 1 & 2 & 3 & 4 & 5 & 6 \\
\hline 1 & 29.500 & 6.000 & 3.500 & 12.750 & 6.833 & 0.750 \\
\hline 2 & 2.250 & 5.000 & 1.500 & 9.000 & 6.833 & 1.000 \\
\hline 3 & 5.000 & 1.750 & 18.250 & 5.750 & 5.167 & 1.000 \\
\hline 4 & 13.750 & 9.000 & 8.000 & 31.250 & 16.333 & 2.750 \\
\hline 5 & 6.500 & 5.333 & 4.500 & 16.667 & 20.333 & 2.167 \\
\hline 6 & 0.000 & 0.250 & 0.000 & 0.500 & 0.667 & 1.000 \\
\hline \multicolumn{7}{|c|}{ Image matrics } \\
\hline & 1 & 2 & 3 & 4 & 5 & 6 \\
\hline 1 & 1 & 0 & 0 & 1 & 0 & 0 \\
\hline 2 & 0 & 0 & 0 & 1 & 0 & 0 \\
\hline 3 & 0 & 0 & 1 & 0 & 0 & 0 \\
\hline 4 & 1 & 1 & 1 & 1 & 1 & 0 \\
\hline 5 & 0 & 0 & 0 & 1 & 1 & 0 \\
\hline 6 & 0 & 0 & 0 & 0 & 0 & 0 \\
\hline \multicolumn{7}{|l|}{ Legend } \\
\hline 1: & \multicolumn{6}{|c|}{ JLIS \& AQ (Interdisciplinary LIS category) } \\
\hline 2: & \multicolumn{6}{|c|}{ JLISS \& NCKULJ (General LIS I category) } \\
\hline 3: & \multicolumn{6}{|c|}{ NCLB \& IMBL (General LIS II category) } \\
\hline 4: & \multicolumn{6}{|c|}{ JOEMLS \& ULJ (Core LIS I category) } \\
\hline 5: & \multicolumn{6}{|c|}{ JLISR, BLIS \& RECT (Core LIS II category) } \\
\hline 6: & \multicolumn{6}{|c|}{ JCEM \& JICLS (Residual category) } \\
\hline
\end{tabular}

\section{CONCLUSION}

This structural equivalence analysis has shed light on the CLIS journal network in Taiwan as follows: First, the block structure of the LIS journal network shows both stability and change through the two individual periods, and also reveals journals' positions and their evolutional change. Second, the structural equivalence based results provide valuable alternative publication outlets for paper re-submission for scholars when a paper has been 
Chen, Y.N.

rejected. Third, several journals competed to gain citations from the similar source journals. Such result is useful for journal editors to gain an image of journals that have similar citation patterns, and know which journals are competitive rivals in terms of $\mathrm{J} 2 \mathrm{~J}$ citation network analysis. Fourth, the core-periphery structure is not only roughly supported by this study both in the first and the second period (i.e., 2001-2007 and 2008-2014), but also for the overall the fourteen years. Fifth, most subgroups have also cited each other both overall and during the two individual periods. Sixth, it is a useful reference to define a clear boundary which journals are eligibly clustered into the LIS category in Taiwan. Lastly, this study has not only provided an overview image of a longitudinal period for structural equivalence analysis in the CLIS journal network in Taiwan, but also examined the evolutional change over two individual periods. The results of this study would be a useful reference to examine the similarities and dissimilarities between English LIS and Chinese LIS journals in Taiwan in terms of the J2J network analysis. One limitation of this study may be target subjects for citations and role-status hypothesis. Citations from English journals and other non-LIS Chinese-language journals in Taiwan are not included in this study. Furthermore, the journal's role-status hypothesis (Doreian and Fararo 1985) has also not been tested in this study. If the aforementioned citations and hypothesis were included, the results and meanings from this study would be enriched.

\section{ACKNOWLEDGEMENT}

This research received no specific grant from any funding agency in the public, commercial, or not-for profit sectors. We thank the reviewers for their helpful suggestions to improve the article.

\section{REFERENCES}

Baker, D.R. 1992. A structural analysis of social work journal network. Journal of Social Service Research, Vol. 15, no. 3-4: 153-168. Available at: https://doi.org/10.1300/J079v15n03_09.

Biehl, M., Kim, H. and Wade, M. 2006. Relationships among the academic business disciplines: A multi-method citation analysis. Omega, Vol. 34, no. 4: 359-371. Available at: https://doi.org/10.1016/j.omega.2004.12.002.

Breiger, R.L., Boorman, S.A. and Arabie, P. 1975. An algorithm for clustering relational data with applications to social network analysis and comparison with multi-dimensional 
scaling. Journal of Mathematical Psychology, Vol. 12, no. 3: 328-383. Available at: https://doi.org/10.1016/0022-2496(75)90028-0.

Burt, R.S. 1987. Social social contagion and innovation: Cohesion versus structural equivalence. American Journal of Sociology, Vol. 92, no. 6: 1287-1335. Available at: https://doi.org/10.1086/228667.

Cason, H. and Lubotsky, M. 1936. The influence and dependence to psychological journals on each other. Psychological Bulletin, Vol. 33, no. 2: 95-103. Available at: https://doi.org/10.1037/h0058635.

Chen, Y.-N. 2018. Structures and patterns of information flow among Chinese-language library and information science journals in Taiwan (2001-2012): A network analysis. Malaysian Journal of Library \& Information Science, Vol. 23, no.1: 33-49. Available at: https://doi.org/10.22452/mjlis.vol23no1.3.

Danell, R. 2000. Stratification among journals in management research: A bibliometric study of interaction between european and american journals. Scientormetrics, Vol. 49, no. 1: 23-38. Available at: https://doi.org/10.1023/A:1005605123831.

Doreian, P. 1985. Structural equivalence in a psychology journal network. Journal of the American Society for Information Science, Vol. 36, no. 6: 411-417. Available at: https://doi.org/10.1002/asi.4630360611.

Doreian, P. and Fararo, T.J. 1985. Structural equivalence in a journal network. Journal of the American Society for Information Science, Vol. 36, no. 1: 28-37. Available at: https://doi.org/10.1002/asi.4630360103.

Doreian, P. 1988. Testing structural-equivalence hypothesis in a network of geographical journals. Journal of the American Society for Information Science, Vol. 39, no. 2: 79-85. Available at: https://doi.org/10.1002/(SICI)1097-4571(198803)39:2<79::AID-ASI2> 3.0.CO;2-C.

Eagly, R.V. 1975. Economics journals as a communication network. Journal of Economic Literature, Vol. 13, no. 3: 878-888. Available at: http://www.jstor.org/stable/2722034.

Gatrell, A.C. and Smith, A. 1984. Networks of relations among a set of geographical journals. Professional Geographer, Vol. 36, no. 3: 300-307. Available at: https://doi.org/10.1111/j.0033-0124.1984.00300.x.

Giannakis, M. 2012. Survey of intellectual structure of the supply chain management in the past two decades: A citation and social network analysis. Journal of Enterprise Information Management, Vol. 25, no. 2: 136-169. Available at: https://pdfs.semanticscholar.org/8761/5f5ad647fc3ee63c0c4cf792c5420605e973.pdf.

Huang, M.H. 2008. Evaluation of journals and researchers in library and information science: Perspectives from citations by Taiwan LIS scholars. Journal of Library and Information Studies, Vol. 6, nos 1/2: 1-27. (in Chinese). Available at: https://doi.org/ 
Chen, Y.N.

10.6182/jlis.2008.6(1.2).001.

Ko, P.-C., Hsung, R.-M. and Lu, K.-W. 2012. A network analysis of inter-journal citations of sociology journals in Taiwan. Journal of Educational Media \& Library Science, Vol. 49, no. 4: 533-561. (in Chinese). Available at: http://joemls.dils.tku.edu.tw/fulltext/ 49/49-4/533-561.pdf.

Leydesdorff, L. 1986. The development of frames of references. Scientometrics, Vol. 9, no. 3-4: 103-125. Available at: https://doi.org/10.1007/BF02017235,

Leydesdorff, L. 2015. The dynamics of journal-journal citation relations: Can hot spots in the sciences be mapped? Proceedings of the Association for Information Science and Technology, Vol. 52, no. 1: 1-4. Available at: https://doi.org/10.1002/ pra2.2015.145052010059.

Leydesdorff, L., de Moya-Anegón, F. and de Nooy, W. 2016. Aggregated journal-journal citation relations in Scopus and Web of Science matched and compared in terms of networks, maps, and interactive overlay. Journal of the Association for Information Science and Technology, Vol. 67, no. 9: 2194-2211. Available at: https://doi.org/10.1002/asi.23372.

Liu, Z. and Wang, C. 2005. Mapping interdisciplinarity in demography: A journal network analysis. Journal of Information Science, Vol. 31, no. 4: 308-316. Available at: https://doi.org/10.1177/0165551505054176.

Lorrain, F. and White, H.D. 1971. Structural equivalence of individuals in networks. Journal of Mathematical Sociology, Vol. 1, no. 1: 49-80. Available at: https://doi.org/10.1080/0022250X.1971.9989788.

McCain, K.W. 1991. Core journal networks and cocitation maps: New bibliometric tools for serials research and management. Library Quarterly, Vol. 61, no. 3: 311-336. Available at: https://doi.org/10.1086/602370.

Pieters, R. and Baumgartner, H. 2002. Who talks to whom: Intra- and interdisciplinary communication of economics journals. Journal of Economic Literature, Vol. 40, no. 2: 483-509. Available at: https://doi.org/ 10.1257/002205102320161348.

Polites, G. and Watson, R.T. 2009. Using social network analysis to analyze relationships among IS journals. Journal of the Association for Information Systems, Vol. 10, no. 8: 595-636. Available at: https://doi.org/ 10.17705/1jais.00206.

Reeves, B. and Borgman, C.L. 1983. A bibliometric evaluation of core journals in communication research. Human Communication Research, Vol. 10, no. 1: 119-136. Available at: https://doi.org/10.1111/j.1468-2958.1983.tb00007.x.

Rice, R.E., Borgman, C.L. and Reeves, B. 1988. Citation networks of communication journals, 1977-1985: Cliques and positions, citations made and citation received. Human Communication Research, Vol. 15, no. 2: 256-283. Available at: https://doi.org/10.1111/ 
j.1468-2958.1988.tb00184.x.

So, C.Y.K. 1988. Citation patterns of core communication journals as assessment of the developmental status of communication. Human Communication Research, Vol. 15 No. 2: 236-255. Available at: https://doi.org/10.1111/j.1468-2958.1988.tb00183.x.

Song, G. and Ye, J. 2009. An analysis of network structures of mutual citation of library and information science journals based on SNA. Journal of Library Science in China, no. 03: 27-34. (in Chinese) Available at: http://www.jlis.cn/jtlscen/ch/reader/ view_abstract.aspx?file_no=20090305\&flag=1.

Sullivan, D., Nerur, S.P. and Balijepally, V. 2011. Source or storer? IB's performance in a knowledge network. Journal of International Business Studies, Vol. 42: 446-457.Available at: https://doi.org/10.1057/jibs.2010.56.

Vugteveen, P., Lenders, R. and Van den Besselaar, P. 2014. The dynamics of interdisciplinary research fields: The case of river research. Scientometrics, Vol. 100, no. 1: 73-96. Available at: https://doi.org/10.1007/s11192-014-1286-7.

Wasserman, S. and Faust, K. 1994. Social network analysis: Methods and applications. Cambridge, UK: Cambridge University Press.

Xhignesse, L.V. and Osgood, C.E. 1967. Bibliographical citation characteristics of the psychological journal network in 1950 and in 1960. American Psychologist, Vol. 22, no. 9: 778-791. Available at: https://doi.org/10.1037/h0024961.

Zawacki-Richter, O. and Anderson, T. 2011. The geography of distance education: Bibliographic characteristics of a journal network. Distance Education, Vol. 32, no. 3: 441-456. Available at: https://doi.org/10.1080/01587919.2011.610287.

Zhao, R. and Wu, S. 2014. The network pattern of journal knowledge transfer in library and information science in China. Knowledge Organization, Vol. 41, no.4: 276-287. Available at: https://doi.org/ 10.5771/0943-7444-2014-4-276.

Zinkhan, G,M., Roth, M.S. and Saxton, M.J. 1992. Knowledge development and scientific status in consumer-behavior research: A social exchange perspective. Journal of Consumer Research, Vol. 19, no. 2: 282-291. Available at: https://doi.org/ $10.1086 / 209302$. 